\title{
TESOUROS DE ÁFRICA PELO MUNDO: A RESTITUIÇÃO DE PATRIMÔNIO CULTURAL FRENTE AO DIREITO INTERNACIONAL
}

\author{
Carolina Nunes Miranda Carasek da Rocha ${ }^{1}$ \\ Juliana Müller ${ }^{2}$
}

Resumo: O objetivo deste artigo é analisar as restituições de bens culturais originários do continente africano frente ao Direito Internacional. Para este fim, foi utilizada pesquisa de natureza básica com fins explicativos e método de abordagem dedutivo com análise qualitativa de meios bibliográficos e documentais. Primeiramente, foi explorada a alienação do patrimônio originário dos povos da África e, após, demonstrada a legislação internacional aplicável a estes objetos de valor. Por último, foi apresentado o movimento internacional pela restituição das riquezas culturais e foram investigados alguns dos principais argumentos que previnem a devolução destes bens.

Palavras-chave: restituição; patrimônio; África; Direito; Internacional.

\section{AFRICA'S TREASURES AROUND THE WORLD: CULTURAL HERITAGE RESTITUTION IN INTERNATIONAL LAW}

\begin{abstract}
The aim of this article is to analyze the restitution of cultural artefacts from the African continent in International Law. For this purpose, research of a basic nature was used for explanatory purposes and a deductive approach method with qualitative analysis of bibliographic and documentary means. Firstly, the alienation of the heritage originating from the peoples of Africa was explored and, afterwards, the international legislation applicable to these objects was demonstrated. Finally, the international movement for the restitution of cultural heritage was presented and some of the main arguments that prevent the return of these artefacts were investigated.
\end{abstract}

Keywords: restitution; heritage; Africa; International; law.

\section{Introdução}

Durante séculos de colonização, o continente africano foi alvo de conquista e pilhagens. Tesouros de valor imensurável, obras de arte das mais variadas, joias e esculturas advindas de inúmeros povos e nações em África foram saqueados e levados para os países colonizadores. Estas riquezas, hoje, encontram-se majoritariamente expostas em museus e

\footnotetext{
${ }^{1}$ Mestre em Direito pela Universidade Federal de Santa Catarina (UFSC). Especialista em Direito Público pela Universidade Regional de Blumenau (FURB). Bacharela em Relações Internacionais pela UFSC. Bacharela em Direito pela Universidade do Sul de Santa Catarina (UNISUL). E-mail: carolinacarasek@ gmail.com.

2 Doutoranda no Programa de Pós-graduação em Direito da Universidade Federal de Santa Catarina. Pesquisadora do Eirenè/UFSC: Centro de Pesquisas e Práticas Pós-coloniais e Decoloniais aplicadas às Relações Internacionais e ao Direito Internacional. Mestra em Direito pelo PPGD/UFSC. E-mail: j.muller@posgrad.ufsc.br.
} 
instituições culturais Ocidentais. Essa conduta, todavia, não se limitou ao período de colonização. Mesmo após a independência dos países explorados, todo dia artefatos culturais e patrimônios históricos dos Estados africanos são roubados e comprados ilegalmente, direcionando-se principalmente à América do Norte e à Europa. Mesmo após a criação de diversas convenções e protocolos internacionais que visam impedir este tráfico, as riquezas de África se esvaem do continente diariamente.

Neste contexto, surgem os processos de reparações por pilhagens, as quais objetivam a devolução destes artefatos históricos às suas culturas de origem. Algumas destas demandas obtiveram sucesso, no entanto, a grande maioria dos pedidos de restituição ainda vem sendo negados. O objetivo deste artigo, portanto, é analisar as restituições de bens culturais originários do continente africano frente ao Direito Internacional.

A fim de cumprir com este objetivo geral, será, primeiramente, explorado como a remoção dos bens culturais da África vem ocorrendo desde a era colonial até os dias de hoje, demonstrando ainda os impactos negativos desta alienação. Após, serão demonstrados os mecanismos do Direito Internacional que versam sobre os bens culturais, ponderando-se acerca da suficiência ou não destes dispositivos jurídicos para a proteção destes artefatos históricos. Por fim, será apresentado o movimento por restituições e expostos alguns dos casos de sucesso no que tange ao retorno de bens culturais, bem como investigados quais são os principais argumentos que impedem tantas demandas de devolução de artefatos de serem atendidas.

A metodologia utilizada foi a de pesquisa de natureza básica com fins explicativos, elaborada a partir de método de abordagem dedutivo com análise qualitativa de meios bibliográficos e documentais, tais como livros, artigos científicos e legislações internacionais.

\section{Pilhagens através dos séculos}

A fim de contribuir com o objetivo geral, este primeiro tópico objetiva explorar como a alienação de artefatos culturais originários da África vem ocorrendo desde a Era Colonial até os dias de hoje, bem como demonstrar de que forma estas pilhagens afetam negativamente os povos do continente africano. Uma quantidade imensurável de itens tais como obras de arte e objetos históricos foram reiteradamente retirados de diferentes regiões da África e levados principalmente para países do Norte Global a partir da invasão colonial europeia. Consoante Müller (2007), a maior parte destes objetos de valor foi coletada entre a 
década de 1870 e a I Guerra Mundial. Estes espólios das guerras coloniais, conforme dispõe o autor, hodiernamente compõem as coleções de museus de famosas cidades do mundo. Costa (2018) e Cerqueira (2020) corroboram que a ocupação colonial removeu muitos bens culturais dos povos a que pertenciam mediante a prática de saques e pilhagens.

Este é o caso, por exemplo, dos famosos bronzes de Benim. Como afirma Hicks (2020), tropas britânicas subtraíram em saques violentos do território que pertence hoje ao país africano objetos que atualmente têm valor monetário de milhões de dólares. As obras de arte dos povos nativos da região encontram-se hoje dispersas em centenas de museus e galerias, localizadas principalmente na Europa e na América do Norte (NIKEL, 2021). Costa (2018) menciona terem sido mais de novecentos bronzes retirados pelos ingleses da região ao final do século XIX, e que, inobstante instituições culturais como o British Museum reconheçam que a alienação se deu através de pilhagem, os mesmos alegam que sua aquisição dos artefatos não teria sido ilegal.

Outro exemplo notório é o do Egito, cujas antiguidades encontram-se espalhadas em museus ao redor do mundo. A Pedra Rosetta, item de valor histórico inestimável para os povos egípcios, encontra-se atualmente no já mencionado British Museum, tendo sido o artefato que deu início à coleção do museu sobre o Egito. Outro objeto importante retirado do Egito é o busto da rainha Nefertiti, que atualmente encontra-se no Neues Museum em Berlim (COSTA, 2018).

Appiah (2009) descreve também as pilhagens em Gana, sua terra natal, na região Asante. O autor afirma que, em 1984, o general britânico Sir Garnet Wolseley viajou para o oeste da África e destruiu Kumasi, a capital Asante. Na expedição, o general autorizou a pilhagem do palácio do Rei Kofi Karikari, que continha um tesouro extraordinário de obras de arte e artefatos culturais. O roubo se repetiu algumas décadas depois no mesmo local, desta vez com o Rei Prempeh, sendo novamente saqueado o palácio real.

A retirada de objetos de valor cultural e histórico do território africano não se limitou, no entanto, ao período colonial. Em diversas regiões, sítios arqueológicos clandestinos continuam a promover a distribuição destes bens, os quais têm como destino principalmente os países do Norte Global. Em Mali, como refere Appiah (2009), escavações indevidas em sítios arqueológicos da região acarretam a alienação de bens culturais importantes para o país, e peças com valor estimado em milhares de dólares continuam a deixar o território africano com destino à venda ilegal. Também a região etíope é ainda nos 
dias atuais vítima de roubos e pilhagens de propriedade cultural em seus sítios arqueológicos. O tráfico ilícito vem sendo combatido pelo governo da Etiópia, mas muitos objetos de grande valor seguem sem proteção suficiente (UNESCO, 2017). Além de sítios arqueológicos, as pilhagens também atingem museus. Na Nigéria, milhões de dólares em artefatos culturais foram roubados de museus nacionais (APPIAH, 2006).

Logo, o continente africano foi e continua sendo alvo de roubo de patrimônio cujo valor histórico e cultural é insubstituível (MÜLLER, 2019). Conforme Shaw (1997), a pilhagem de obras culturais do continente africano em escala colossal é a manifestação da contínua exploração do Sul Global. Da mesma forma, Udvardy, Giles e Mitsanze (2003) sabiamente sustentam que o tráfico de bens culturais é uma forma de imperialismo econômico e cultural do Ocidente. Os negociantes destas obras fecham seus olhos para o impacto individual e comunitário que causam à integridade cultural de um povo, trazendo danos irreparáveis. Estes danos não constituem apenas na falta de lucratividade que a atividade de pilhagem gera para os países africanos, mas na impossibilidade de acesso para suas populações às suas obras históricas e simbólicas.

De fato, os prejuízos da alienação de seus próprios objetos históricos são incalculáveis para os povos do continente. Não se trata, como visto, apenas do valor monetário das obras e artefatos, mas seu valor cultural. Como exemplo disso, pode-se citar o trabalho de Udvardy, Giles e Mitsanze (2003) que acompanhou o destino de centenas de vigangos, estátuas originárias do povo Mijikenda, da costa leste da África, os quais foram roubados em enormes quantidades, sendo destinados ao mercado global. Atualmente, os povos Mijikenda estão localizados na costa do Quênia e Tanzânia. Os vigangos representam os ancestrais de suas famílias, e, para estes nativos, removê-los do local de origem é uma grande ofensa e agouro para seus membros. Estes artefatos históricos, tão importantes para estas comunidades, tiveram como destino principalmente os Estados Unidos e a Europa.

Como elabora Hicks (2020), enquanto objetos sagrados saqueados durante os massacres coloniais continuarem a serem exibidos em galerias de arte e museus de história por todo o mundo, os mesmos servem como uma propaganda violenta da suposta superioridade Ocidental acima das civilizações africanas. Trata-se de uma construção de memórias que satisfaz o racismo científico e representa o Sul Global como um local de retrocesso. Estas instituições culturais que detém estes objetos são cúmplices destas violações e da destruição cultural das comunidades atingidas. No mesmo sentido, Cerqueira (2020) aduz 
que a missão colonizadora também envolveu o domínio cultural. Isso porque, além de muitos povos do continente africano terem sua história melhor representadas em museus da Europa do que em sua própria região, as exposições estrangeiras defendem o projeto colonial e são marcadas pelo etnocentrismo, pois a exibição destes artefatos culturais denota um interesse na história de povos tidos como "diferentes", como "os outros".

Ferreira (2014) observa ainda que objetos retirados de seu meio cultural constantemente perdem seu significado, passando de símbolos históricos para artefatos de gozo estético. Para Vrdoljak (2006), as obras saqueadas representam para os povos colonizados uma perda de soberania e o domínio do poder colonizador; e, portanto, a devolução destes bens significaria igualmente uma retomada da identidade autônoma destas coletividades e o restabelecimento da soberania dessas nações. Outrossim, Tahan (2010) destaca que o colonialismo atingiu não somente as populações passadas, mas também as novas, ao negar acesso à sua herança cultural.

Müller (2007) corrobora que os séculos de saques e pilhagens permanecem vivos na memória dos povos outrora colonizados, e é natural que as sociedades que fabricaram os objetos desejem ter acesso a eles para (re)descobrir a própria história. Ogbechie (2010) evidencia que os povos africanos, que foram os que produziram estes artefatos, foram privados de seu próprio patrimônio cultural através da conquista e da pilhagem, e, após, foram também impedidos de ter autoridade para determinar como esses artefatos devem se disseminar, isso sem mencionar que não recebem nenhum benefício econômico pela venda e disposição das artes e suas imagens. Dessa forma, estas nações têm negada a oportunidade de uma real interação com os produtos culturais de seus ancestrais, seus simbolismos e seus significados. Appiah (2009) observa também que a conexão que liga objetos culturais às pessoas é um simbolismo produzido por seus ancestrais, conectando a arte à identidade, um vínculo forte que deve ser reconhecido pela sociedade internacional.

Assim exposto, pode-se verificar que as pilhagens no continente africano já produziram prejuízos irreparáveis, e, ainda assim, continuam a acontecer no tempo presente em largas escalas. Ademais, tendo sido exposta a importância da permanência do patrimônio cultural em sua comunidade originária, resta claro que é necessária a restituição desses bens aos povos do continente africano.

\section{Serão as soluções do Direito Internacional suficientes?}


Tendo sido analisada a realidade da subtração de artefatos históricos do continente africano tanto no passado colonial como no presente, este tópico pretende contribuir com o objetivo geral a partir do estudo dos mecanismos do Direito Internacional que tratam sobre estes bens, ponderando-se acerca da suficiência ou não destes dispositivos jurídicos para proteção dos bens culturais.

Em 1815, o Congresso de Viena, ao dispor sobre as reparações com as quais a França deveria arcar após a derrota napoleônica, estabeleceu uma primeira linha de pensamento sobre o patrimônio cultural nacional. Foi então estipulado que os franceses haviam violado a lei ao saquear obras de arte de diferentes países e que esta subtração deveria ser reparada. A partir desses eventos, os objetos de valor histórico passaram a ser vistos na legislação internacional não somente por seu potencial monetário, mas também como parte da cultura de uma nação. Desta forma, começou a ser reconhecida a ligação entre um artefato histórico e seu local de origem. Além disso, este esboço serviu de parâmetro para tratados internacionais que viriam a ser traçados posteriormente (VRDOLJAK, 2006).

É o caso da Convenção sobre as Medidas que Devem ser Adotadas para Impedir e Proibir a Importação, a Exportação e a Transferência de Propriedades Ilícitas de Bens Culturais, de 1970, da UNESCO, promulgada no Brasil através do Decreto nº 72.312 de 31 de maio de 1973. O desenvolvimento destas medidas por parte da UNESCO deu-se para tentar impedir as subtrações desenfreadas de objetos de valor dos territórios africanos colonizados pelos europeus. A normativa foi criada para combater a pilhagem em sítios arqueológicos e o tráfico ilícito de itens de valor cultural e histórico. O documento foi o primeiro instrumento internacional a contextualizar legalmente a luta contra o tráfico ilegal de patrimônio cultural em tempos de paz (UNESCO, 1970; UNESCO, 2020a).

A Convenção definiu como bens culturais aqueles "designados por cada Estado como de importância para a arqueologia, a pré-história, a história, a literatura, a arte ou a ciência" (UNESCO, 1970, n. p.). Além de oferecer benefícios para as partes que a ratifiquem, a Convenção também traz obrigações de adotar medidas de proteção em seus territórios, como legislação nacional, inventários nacionais, códigos de condutas entre os negociantes de bens culturais, programas educativos, etc. Os Estados, além disso, comprometem-se a utilizar certificados de exportação para estes bens, estão suscetíveis a sanções penais em caso de descumprimento das cláusulas e devem cumprir com a manutenção de registro da origem dos artefatos (UNESCO, 1970). 
Ademais, ratificando a Convenção, os Estados-partes comprometem-se a retornar a propriedade cultural roubada, devolvendo-a à nação da qual o artefato tiver sido subtraído. Colaciona-se o Artigo $7^{\circ}$, b, II da referida legislação:

\begin{abstract}
Os Estados-Partes na presente Convenção, se comprometem a: tomar as medidas apropriadas, mediante solicitação do Estado de origem Parte na Convenção, para recuperar e restituir quaisquer bens culturais roubados e importados após a entrada em vigor da presente Convenção para ambos os Estados interessados, desde que o Estado solicitante pague justa compensação a qualquer comprador de boa fé ou a qualquer pessoa que detenha a propriedade legal daqueles bens. As solicitações de recuperação e restituição serão feitas por via diplomática. A parte solicitante deverá fornecer, a suas expensas, a documentação e outros meios de prova necessária para fundamentar sua solicitação de recuperação e restituição. As partes não cobrarão direitos aduaneiros ou outros encargos sobre os bens culturais restituídos em conformidade com este artigo. Todas as despesas relativas à restituição e à entrega dos bens culturais serão pela parte solicitante (UNESCO, 1970, n. p.).
\end{abstract}

A Convenção, contudo, não é retroativa, o que significa que é apenas aplicável para objetos culturais roubados ou ilicitamente exportados de um Estado-parte para outro após a entrada em vigor do diploma legal para ambos os envolvidos. Esta condição reduz enormemente a abrangência de aplicabilidade da Convenção, bem como limita sua eficácia. Udvardy, Giles e Mitsanze (2003) observam que, por não ser retroativa, a Convenção da UNESCO não atende os milhares de artefatos de países da África que já estão em museus do exterior - majoritariamente na Europa e nos Estados Unidos.

Ademais, existe a barreira de que a Convenção reconhece como partes apenas os Estados, não havendo representação indígena, étnica ou de comunidades locais que estejam diretamente envolvidas com esforços de repatriação de seus bens. Logo, quando os Estados apresentam requisições para o retorno de propriedade cultural importante, frequentemente estes estão interessados em resguardar a propriedade como sua, e não em retorná-la à comunidade de origem. Dessa forma, um artefato pode ser apropriado para herança nacional, mas ainda assim ser alienado de seu contexto cultural e histórico (UDVARDY, GILES e MITSANZE, 2003).

Todavia, a Convenção ainda é válida atualmente e - independentemente das bem colocadas críticas à sua efetividade e abrangência - países continuam a buscá-la para proteção aos seus bens culturais. Um exemplo é a Etiópia que ratificou a Convenção de 1970 no ano de 2017. Conforme relata a UNESCO, após anos sendo vítima de roubos e pilhagens, em 2006 o país africano tomou medidas de nível nacional para obter toda a legislação necessária para 
ratificar a normativa, sendo o pedido oficial submetido apenas em 2017. Na região leste da África, a Etiópia juntou-se à Madagascar, Maurício, Ruanda, Seicheles e Tanzânia, os quais também fazem parte da Convenção (UNESCO, 2017).

Em 1973, a Assembleia Geral da ONU aprovou sua Resolução 3187 sobre a "Restituição de obras de arte a países vítimas de expropriações", oportunidade em que a Organização Internacional lamentou a remoção de objetos de arte de um país para outro, frequentemente como resultado da ocupação colonial ou estrangeira, e apelou aos Estados membros pela restituição imediata desses bens. Esta Resolução denotou o entendimento de que a maioria dos Estados membros da ONU apoiava a devolução dos bens culturais retirados pela ocupação colonial. Uma década depois, em 1983, a mesma Assembleia aprovou a Resolução 3834 acerca do "Retorno ou restituição de propriedade cultural para os países de origem", na qual chamou a atenção para a necessidade da restituição dos bens culturais aos países de origem em busca de um fortalecimento da cooperação entre a sociedade internacional (CERQUEIRA, 2020; FERREIRA, 2014; ONU, 1973).

Em 1978, a UNESCO constituiu, em uma Conferência Geral em Paris, o Comitê Intergovernamental para a Promoção do Retorno dos Bens Culturais aos seus Países de Origem ou sua Restituição em caso de Apropriação Ilícita. O Comitê, constituído por vinte e dois Estados membros, teria o intuito de auxiliar a resolução de conflitos no que tange às demandas de restituição de bens culturais ilicitamente apropriados durante ocupações estrangeiras. Uma vez que as negociações diretas entre os Estados interessados em determinado objeto não chegassem a um consenso, o caso poderia ser submetido ao Comitê juntamente com a descrição do artefato, de seu local e estado de conservação, dentre outras informações, tais como o modo e a época em que o bem deixou seu local de origem (COSTA, 2018).

Alguns anos depois, a resolução 42/7 votada pela Assembleia Geral da ONU em 1987 versou sobre a devolução dos bens culturais de valor espiritual e cultural aos seus países de origem, alegando que esta reparação tem importância para que os povos envolvidos construam coleções representativas de seu patrimônio cultural (MÜLLER, 2007; ONU, 1987). Já em 1995, esta discussão tomou fôlego com a aprovação da Convenção para Retorno Internacional de Bens Culturais Roubados ou Ilicitamente Exportados por parte da UNIDROIT. O objetivo da Convenção foi facilitar a restituição e o retorno de bens culturais, 
estabelecendo regras de natureza jurídica para a regulamentação da restituição de artefatos de valor entre os Estados-partes (CERQUEIRA, 2020; UNIDROIT, 1995).

Consiste, portanto, em uma cooperação internacional na qual os signatários comprometem-se com o retorno de objetos culturais roubados ou exportados ilegalmente, permitindo que estas demandas sejam processadas diretamente em suas cortes nacionais. Além disso, a Convenção de 1995 da UNIDROIT cobre todos os bens patrimoniais históricos roubados, não apenas os inventariados e previamente declarados, estipulando que todos devem ser repatriados (UNIDROIT, 1995). Todavia, seu capítulo II, artigo $3^{\circ}$ traz uma limitação:

Artigo $3^{\text {o: }}$ Qualquer solicitação de restituição deve ser apresentada dentro de um prazo de três anos a partir do momento em que o solicitante toma conhecimento do lugar onde se encontra o bem cultural e da identidade do possuidor, e, em qualquer caso, dentro de um prazo de cinquenta anos a partir do momento do furto (UNIDROIT, 1995, n. p.).

Ferreira (2014) sustenta que o artigo $3^{\circ}$ traz uma barreira temporal importante, a qual inviabiliza muitos casos. Além disso, o autor salienta outra grande dificuldade: todo o custo do processo do retorno precisa ser pago pelos Estados requerentes, que em sua maioria possuem menos recursos que os Estados requeridos, o que dificulta os processos de retorno. Nesse sentido, o autor aponta que é necessário debater o retorno dos bens culturais saqueados na era colonial por parte das metrópoles europeias aos países de origem destes objetos, como uma reparação histórica a estes povos que sofreram com reiteradas violações e seguem sendo atingidos por novas formas de opressão na contemporaneidade. Igualmente, destaca o potencial das restituições de possibilitar um diálogo entre as esferas nacionais sobre o direito à cultura.

No ano passado, ao comemorar os 50 anos da Convenção de 1970, a UNESCO referiu que o tráfico ilícito de bens culturais ainda é largamente praticado e constitui um flagelo contra o qual a sociedade internacional deve seguir lutando. Segundo a Organização, a cobiça por estes objetos disparou, e a vulnerabilidade dos sítios em zonas de conflito são os que apresentam o maior desafio na repressão desses crimes. Milhares de artefatos arqueológicos e obras de arte são ainda alvo de redes internacionais de tráfico, as quais vem sendo desmanteladas no âmbito internacional, principalmente pelos 140 signatários da Convenção de 1970. Apesar do enfrentamento a este comércio clandestino, no entanto, a 
demanda por estas antiguidades e obras de arte segue alimentando o deslocamento irregular dos bens culturais (UNESCO, 2020b).

Como visto, o desenvolvimento de instrumentos internacionais que abram caminhos para a proibição do tráfico e a restituição de bens é um importante passo em direção à supressão destas condutas criminosas e à uma reconciliação internacional. No entanto, conforme demonstrado, as normativas até agora desenvolvidas possuem abrangência restrita para que estas devoluções ocorram. É necessário, portanto, a elaboração de novos meios jurídicos e diplomáticos através dos quais seja facilitado o retorno de artefatos alienados na era colonial e daqueles que seguem a ser retirados de seus territórios originários irregularmente todos os dias.

\section{As demandas pela restituição de patrimônio histórico africano}

Tendo sido estudados os dispositivos do Direito Internacional que se dedicam à proteção de bens culturais e sua eficácia, este tópico tem como escopo apresentar o movimento por restituições e analisar alguns dos casos de sucesso no que tange ao retorno de artefatos históricos, bem como investigar quais os argumentos que previnem outras tantas demandas reparatórias de serem atendidas.

Conforme Merryman (2006), as solicitações de reparação por pilhagem datam do século XIX. Os artefatos retirados antes desse período eram vistos como espólios de guerra e eram considerados uma prática legal, uma consequência natural da vitória. No continente africano, consoante Müller (2007), o movimento pela restituição de bens culturais espoliados desenvolveu-se no início da década de 1980, aumentando paralelamente à visibilidade dos museus Ocidentais. Segundo o autor, a Proclamação de Abuja de 2003, ao referir-se à dívida para com os povos da África, menciona o retorno dos bens roubados de seu território, convidando à restituição dos artefatos culturais aos seus proprietários legítimos.

Em 1980, a Nigéria demandou do Reino Unido a devolução de centenas de placas de bronze saqueadas dos reinos que ocupavam o território que posteriormente se tornaria a nação nigeriana. Deste pedido seguiram-se muitos outros. A Etiópia exigiu, também dos britânicos, o retorno de objetos que foram saqueados de seu território durante o cerco de Magdala, em 1868. O Egito, por sua vez, demandou da Alemanha a devolução do já mencionado busto de Nefertiti. E, no Benim, descendentes do rei Béhanzin requisitaram dos franceses a restituição 
do tesouro real que consta hoje no acervo do museu Quai Branly, em Paris. (MÜLLER, 2007).

Cerqueira (2020) menciona que no Senegal, o Ministro da Cultura alega que o novo Museu das Civilizações Negras, inaugurado em Dacar em 2018, tem condições de guardar e conservar os bens culturais originários do país e mostra-se pronto para negociar com a França a restituição dos artefatos históricos da região senegalesa. Também o governo da Costa do Marfim possui uma lista com centenas de obras-primas cuja restituição é demandada pela nação. Pode-se, ainda, fazer referência ao pedido da República Democrática do Congo por obras de arte que se encontram na Bélgica, e à escultura da Rainha de Bangwa, peça de grande significado para povos nativos do território camaronense e que hoje se encontra em Paris. O retorno do artefato à Camarões vem sendo exigido por líderes tradicionais dos povos Bangwa (VICENTE, 2018).

Em 2018, o presidente francês Emmanuel Macron encomendou um relatório oficial acerca dos tesouros espoliados pela nação francesa durante a era colonial e também após este período. O pedido foi feito a dois especialistas, a historiadora francesa Bénédicte Savoy e o economista senegalês Felwine Sarr, ambos defensores da restituição de bens culturais ao continente africano. O escopo do documento é estabelecer um diálogo entre África e Europa para repensar tanto o passado como o futuro no que tange aos artefatos históricos dos povos africanos (VICENTE, 2018). O relatório menciona a necessidade de dar acesso aos jovens à sua própria história e ancestralidade. Os jovens da África, conforme seus autores, têm direito a seu próprio patrimônio cultural e artístico (SAVOY e SARR, 2018).

Vicente (2018) salienta que o relatório pode dar início tanto a uma revolução nas relações entre as nações europeias e suas ex-colônias como, igualmente, não resultar em nenhuma medida, perdendo-se em obstáculos jurídicos e políticos. Trata-se de um novo desafio para as capitais europeias - a França, por exemplo, é o lar de pelo menos 90.000 objetos cuja origem é a África subsaariana, sendo que a majoritária parte destes artefatos se encontra em Paris, no Museu de Quai Branly. O relatório foi recebido pelos museus da Europa, a princípio, com diplomacia, mas os mesmos não parecem dispostos a abdicar de seus inventários. Já no continente africano, os povos e governos das nações espoliadas reagiram com entusiasmo ao documento, renovando suas expectativas pelo retorno de seus bens culturais originários (VICENTE, 2018).

Para Savoy e Sarr (2018), 
A melhor abordagem e método para a restituição de objetos culturais africanos é estabelecer outra ética relacional. Ao trabalhar através do espaço do simbólico, este espaço torna-se tectônico e seus tremores secundários, e os novos valores que ele inaugura, não deixarão nenhum local de troca entre as sociedades europeias e africanas ileso (seja ele econômico, político ou social). A restituição de itens culturais africanos iniciará, portanto, uma nova economia de relações cujos efeitos não se limitarão aos espaços culturais ou de intercâmbio museográfico (SAVOY e SARR, 2018, p. 87 e 88, tradução nossa).

Os autores sustentam que os bens culturais, ainda que arrancados de suas origens pela violência colonial, foram acolhidos e cuidados por diversas gerações de curadores em seus locais na Europa, e por isso também pertencem um pouco a este continente agora. Este argumento demonstra que é necessária uma nova racionalidade para mediar os conflitos pela guarda das milhares de obras de arte e objetos históricos em questão (SAVOY e SARR, 2018).

Ao redor do mundo, muitas reparações por pilhagens têm obtido sucesso em restituir artefatos de valor cultural para os países com os quais os objetos possuem ligação histórica. Costa (2018) menciona a devolução por parte da Itália de mais de 10.000 artefatos ao Equador em 1983 a partir da atuação da UNESCO e, ainda, a restituição à Turquia de 7.000 cuneiformes que se encontravam na Alemanha. A autora faz ainda referência ao comemorado retorno do Obelisco de Axum ao povo etíope em 2005, monumento que havia sido retirado do território da Etiópia em 1937 por Mussolini e levado para a Itália.

Em 2010, uma coleção de antiguidades Incas de Machu Picchu foi devolvida ao Peru. Os artefatos estavam na Universidade Yale, dos Estados Unidos, instituição que segue na posse da maior parte dos objetos da sociedade Inca escavados por Hiram Bingham III em suas expedições ao país sul-americano no início do século XX. O museu da Universidade, o Peabody Museum, argumentou que o motivo de continuar a reter diversas das obras Incas é serem os bens alvos de estudo pela instituição (NPR, 2010).

Além desta negociação com o Peru, em 2017, a Universidade de Yale também concordou em devolver artefatos de seu museu ao povo Mohegan, nativos da região de Uncasville dos Estados Unidos. Os objetos, que haviam sido obtidos por explorações arqueológicas na década de 1930 e vinham sendo demandados por sua comunidade originária há muitos anos, foram transferidos ao Museu Tantaquidgeon, administrado pelos povos Mohegan (GOSSELIN, 2017).

No mesmo ano, o Camboja recuperou, após um longo processo, joias preciosas que haviam sido retiradas do tempo Angkor Wat em 1970, quando o país se encontrava em uma 
guerra civil. Os acessórios de ouro pertenciam originalmente ao Império Khmer, uma dinastia importante para a história do Camboja e também do Vietnã e Laos. Os itens foram descobertos em um catálogo virtual de um comerciante de obras de arte londrino, e foram devolvidos ao seu local de origem (NST, 2017).

Ainda em 2017, o Programa de Recuperação e Proteção de Bens Culturais do Ministério das Relações Exteriores do governo da Guatemala logrou repatriar dezoito peças arqueológicas que haviam sido arrecadadas de maneira ilícita do país na década de 1960. Os itens foram localizados na Alemanha, Itália e Suíça (MINISTERIO DE RELACIONES EXTERIORES, 2017).

Estes casos trazem esperança de uma justiça internacional na disposição de bens culturais. Todavia, sabe-se que não representam a grande massa dos artefatos históricos desviados por séculos de seus territórios e povos de origem, principalmente tratando-se da exploração do continente africano e das milhares de peças de valor inestimável que foram subtraídas durante a colonização europeia e hoje compõem valiosíssimas coleções em museus Ocidentais.

A maioria dos pedidos de restituição de bens culturais e obras de arte são negados, e os museus Ocidentais elencam uma série de argumentos para isso. Muitos alegam, por exemplo, que não estão à serviço do país em que se encontram, mas que se consideram museus universais com a missão de encorajar a produção de conhecimento junto a todos os povos e nações. Referem, ainda, que a devolução de objetos pode acarretar a destruição dos mesmos (MÜLLER, 2007).

Essa menção à uma suposta incapacidade dos museus da África de conservar e restaurar seus próprios bens culturais de maneira adequada é ecoada por diversas outras instituições. Estas alegações, no entanto, podem ser contestadas à luz de países como o Egito, que vem investindo em museus novos e infraestrutura de alto padrão, além de possuir um grande fluxo de turistas, inclusive oriundos de países europeus e norte-americanos (COSTA, 2018).

Outra justificativa para fundamentar a não devolução dos artefatos é que, não existindo Estados no continente africano quando as pilhagens e violações ocorreram, não poderia ser considerada ilegal a retirada dos bens culturais das colônias (FERREIRA, 2014). De fato, como visto, a legislação internacional vigente não é retroativa. No entanto, o Direito 
Internacional deve também se atentar para a importância cultural desses bens para as nações cuja história pertencem, e de quem foram alienados.

Ferreira (2014) afirma que, apesar das muitas razões colocadas pelos administradores dos grandes museus Ocidentais, o grande motivo que leva à não devolução dos artefatos históricos não é a conservação dos bens ou outra preocupação senão o montante de capital que a exposição dos bens africanos gera à estas instituições e, ainda, as possíveis indenizações a serem pagas como reparações ao reconhecer o colonialismo como uma ofensa à humanidade. Diante deste cenário, muitos autores propõem medidas conciliadoras, como é o caso de Cuno (2009), que propõe um intercâmbio dos objetos históricos entre os países, de forma a possibilitar que mais pessoas ao redor do mundo tenham acesso aos mesmos.

A ocupação colonial e militar que levou ao saque das riquezas dos Estados africanos acarretou a destruição das estruturas sociopolíticas destas sociedades e condenou estes povos ao apagamento de suas referências culturais, aliado ainda à imposição da cultura europeia (FERREIRA, 2014). O retorno dos artefatos culturais destes países ao seu local de origem permite, como refere Costa (2018), o acesso destas comunidades à sua própria história. Corrêa (2011) corrobora que a reparação das obras simbolizaria o reconhecimento dos erros passados para com estas sociedades.

É inegável a necessidade de os povos e culturas da África terem acesso aos objetos e obras de arte que se originam de suas próprias histórias. Esta reconciliação, consoante Ferreira (2014), é indispensável para lidar com as chagas do colonialismo e das violências contra as nações africanas, um esforço que a comunidade internacional precisa realizar para reparar os danos destas violações no passado e no presente.

\section{Conclusão}

Como exposto, as pilhagens de artefatos históricos no continente africano já produziram danos irreparáveis para as nações das quais estes bens culturais se originaram, e esta violação não pertence somente ao passado colonial, mas segue acontecendo em largas escalas. Restou, igualmente, demonstrada a importância de que este patrimônio seja restituído às comunidades de origem.

A partir da análise da legislação internacional que concerne bens culturais foi possível compreender que o Direito Internacional, ainda que possua mecanismos com intuito de barrar 
o tráfico de objetos históricos, possui diversas limitações e eficácia restrita no que concerne à proteção destes artefatos. Logo, faz-se necessária a elaboração de meios jurídicos e diplomáticos que facilitem o retorno de artefatos alienados aos territórios a que pertencem.

Ademais, tendo sido apresentado o movimento por restituições e vistos alguns dos casos que obtiveram sucesso na devolução de bens culturais, foi possível concluir que a maior parte destas demandas seguem insatisfeitas devido a argumentos colocados pelos museus Ocidentais, como o de que estes objetos estariam sendo melhor conservados e protegidos do que nos países africanos. As razões elencadas, no entanto, não parecem sobrepor a ganância destas instituições culturais em manter as riquezas de África em suas coleções, mesmo cientes de que as comunidades originárias têm direito de ter acesso aos seus próprios bens culturais e históricos.

Desta discussão, surgem propostas conciliatórias que sugerem restituições parciais ou o compartilhamento deste patrimônio. Trata-se, portanto, de uma tema que exige atenção e esforço por parte da comunidade internacional a fỉm de que possam ser alcançadas soluções, tendo em vista que a restituição de artefatos não diz respeito apenas à posse destes bens, mas a sua importância cultural e histórica para suas comunidades originárias. A devolução deste patrimônio consiste, desta forma, em uma oportunidade de contar histórias até então silenciadas acerca da violência colonial que atingiu o continente africano e cujas consequências seguem presentes na atualidade.

\section{Referências}

APPIAH, Kwame Anthony. Whose Culture is it? Em: Whose Culture? Ed. James Cuno. Princeton University Press, 2009, p. 71-86.

CERQUEIRA, Amanda Patrycia Coutinho de. Diáspora africana na espoliação e restituição de bens culturais: um ensaio acerca das discussões contemporâneas. Em: ODEERE: Revista do Programa de Pós-Graduação em Relações Étnicas e Contemporaneidade, v. 5, n. 9, junho de 2020, p. 379-390. Disponível em: https://periodicos2.uesb.br/index.php/odeere/article/view/5741/4839 Acesso em: 05 abr. 2021.

CORRÊA, Sílvio Marcus de Souza. História, memória e comemorações: em torno do genocídio e do passado colonial no sudoeste africano. Em: Revista Brasileira de História, v. 31, n. 61, 2011, p. 85-103.

COSTA, Karine Lima da. Pensar o patrimônio cultural por meio da repatriação e restituição de bens culturais. Em: Patrimônio e Memória, v. 14, n. 2, julho-dezembro, 2018, p. 256-271. 
Disponível em: https://pem.assis.unesp.br/index.php/pem/article/view/876 Acesso em: 05 abr. 2021.

CUNO, James. Whose Culture? The Promise of Museums and the Debate over Antiquities. Princeton: Princeton University Press, 2009.

FERREIRA, Carlos Serrano. Restituição dos bens culturais retirados no contexto do colonialismo: instrumento de desenvolvimento e de diálogo intercultural. Em: Cadernos de Sociomuseologia, $\quad$ v. $47,2014.2$ Disponível em: https://revistas.ulusofona.pt/index.php/cadernosociomuseologia/article/view/4534. Acesso em: 05 abr. 2021.

GOSSELIN, Kenneth R. Yale agrees to return hundreds of artifacts to mohegans. 2017. Disponível em: http://www.courant.com/business/hc-biz-yale-mohegan-artifacts-20171117story.html. Acesso em: 2 abr. 2021.

HICKS, Dan. The British Museums: The Benin Bronzes, Colonial Violence and Cultural Restitution. Londres: Pluto Press, 2020.

MERRYMAN, John Henry. Imperialism, Art and Restitution. New York: Cambridge University Press, 2006.

MINISTERIO DE RELACIONES EXTERIORES. Guatemala logra repatriar piezas arqueológicas $2017 . \quad$ Dobadas. 2 em: https://www.minex.gob.gt/noticias/Noticia.aspx?ID=27425. Acesso em: 3 abr. 2021.

MÜLLER, Bernard. Museus, pilhagem colonial e reparações. 2007. Disponível em: http://diplomatique.org.br/museus-pilhagem-colonial-e-reparacoes/. Acesso em: 24 mar. 2021.

MÜLLER, Juliana. Reparações por colonialismo e escravidão nas ex-colônias britânicas do Caribe: uma perspectiva para a descolonização do Direito Internacional. Orientadora Karine de Souza Silva. 168p. Dissertação (mestrado) - Universidade Federal de Santa Catarina, Centro de Ciências Jurídicas, Programa de Pós-graduação em Direito, Florianópolis, 2019. Disponível em: https://repositorio.ufsc.br/handle/123456789/215175. Acesso em: 24 mar. 2021.

NIKEL, Isabella Pereira. Eu peço pela memória de África: A cultura do imperialismo no museu moderno "universal" a partir do estudo da expropriação cultural e do memoricídio no Reino de Benin. Orientadora Karine de Souza Silva. 112 p. Trabalho de Conclusão de Curso (graduação) - Universidade Federal de Santa Catarina, Centro Sócio Econômico, Graduação em Relações Internacionais, Florianópolis, 2021. Disponível em: https://repositorio.ufsc.br/handle/123456789/223131. Acesso em: 23 mar. 2021. 
NPR. Yale Returns Machu Picchu Artifacts To Peru. National Public Radio. 2010. Disponível em: https://www.npr.org/2010/12/15/132083890/yale-returns-machu-picchuartifacts-to-peru. Acesso em: 4 abr. 2021.

NST. Looted Angkor jewellery returned to Cambodia. New Straits Times. 2017. Disponível em: https://www.nst.com.my/world/2017/12/309847/looted-angkor-jewelleryreturned-cambodia. Acesso em: 4 abr. 2021.

OGBECHIE, Sylvester Okwunodu. Who Owns Africa's Cultural Patrimony? Em: Critical Interventions, v. 4, 2010, p. 2-3.

ONU. Restitution of works of art to countries victims of appropriation. 1974. Disponível em: https://digitallibrary.un.org/record/190996?ln=en. Acesso em: 5 abr. 2021.

SAVOY, Bénédicte; SARR, Felwine. The Restitution of African Cultural Heritage. Toward a New Relational Ethics. 2018. Disponível em http://restitutionreport2018.com/sarr savoy en.pdf. Acesso em: 5 abr. 2021.

SHAW, T. The Contemporary Plundering of Africa's Past. Em: African Archaeological Review, v. 14, n. 1, 1997.

TAHAN, Lina. Challenging Colonialism and Nationalism in Lebanese Archaeological Museums. Em: Near Eastern Archaeology, v. 73, n. 2/3, 2010, p. 195-197. Disponível em: http://www.jstor.org/stable/25754049. Acesso em: 4 abr. 2021.

UDVARDY, M; GILES, L; MITSANZE, J. The Transatlantic Trade in African Ancestors: Mijikenda Memorial Statues (Vigango) and the Ethics of Collecting and Curating NonWestern Cultural Property. Em: American Anthropologist, v. 105, n. 3, 2003, pp. 566-580.

UNESCO. Ethiopia ratifies the UNESCO 1970 Convention to reinforce its fight against illicit trafficking of cultural property. 2017. Disponível em: http://www.unesco.org/new/en/member-states/single-

view/news/ethiopia_ratifies_the unesco_1970_convention_to_reinforce_it/. Acesso em: 4 abr. 2021.

UNESCO. Traficantes de arte: pilhagem das identidades dos povos. 2020b. Disponível em: https://pt.unesco.org/courier/2020-4/traficantes-arte-pilhagem-das-identidades-dos-povos. Acesso em: 4 abr. 2021.

UNESCO. Uma Convenção pioneira. 2020a. Disponível em: https://pt.unesco.org/news/uma-convencao-pioneira. Acesso em: 3 abr. 2021.

UNIDROIT. Convenção sobre Bens Culturais Roubados ou Ilicitamente Exportados. 1995. Disponível em: http://www.planalto.gov.br/ccivil_03/decreto/d3166.htm. Acesso em: 3 abr. 2021. 
VICENTE, Álex. Devolução dos tesouros africanos coloca em alerta os museus etnográficos. $2018 . \quad$ Disponível em: https://brasil.elpais.com/brasil/2018/12/14/cultura/1544801008_489541.html. Acesso em: 05 abr. 2021.

VRDOLJAK, Ana Filipa. International Law, Museums and the Return of Cultural Objects. Cambridge: Cambridge University Press, 2006. 